\title{
Commentary
}

\section{Teaching Organic Chemistry at the American University of Beirut Through the COVID-19 Pandemic}

\author{
Bilal R. Kaafarani \\ Department of Chemistry, American University of Beirut, Beirut, Lebanon \\ Email address: \\ bilal.kaafarani@aub.edu.lb
}

To cite this article:

Bilal R. Kaafarani. Teaching Organic Chemistry at the American University of Beirut Through the COVID-19 Pandemic. Science Journal of Education. Vol. 8, No. 6, 2020, pp. 133-138. doi: 10.11648/j.sjedu.20200806.11

Received: September 22, 2020; Accepted: October 9, 2020; Published: November 11, 2020

\begin{abstract}
The COVID-19 pandemic has single-handedly overturned a traditional lecture-based educational system at universities on a global scale. The required abrupt move to an online platform for education has caused tremendous challenges for educational systems in general and specifically also in the chemical sciences. In Lebanon particularly, the COVID-19 pandemic raked havoc on a country entrenched in popular uprising and riddled by an economic collapse observing unprecedented devaluation of the national currency. In this situation, the move to online education had caused tremendous stress and burden for faculty and students raising the need to develop mitigation strategies by embracing reduction in material and a careful consideration of students' mental health. This commentary presents the author's experience of delivering undergraduate Organic Chemistry courses at the American University of Beirut (AUB) through the COVID-19 pandemic, during the spring and summer 2020 semesters. While the author's pre-recorded lectures of Organic Chemistry I were vital to the online delivery of course material, this commentary particularly highlights the inclusion of supplementary online assignments that include: videos to illustrate a covered organic chemistry concept, instructional videos to explain a multiple choice question (MCQ) of their creation, a cartoon to exemplify an organic chemistry concept, a cartoon to reflect on studying organic chemistry during the COVID-19 pandemic and a group assignment that allowed students to assume social responsibility.
\end{abstract}

Keywords: COVID-19 Pandemic, Organic Chemistry, Online Assignments, Cartoons, Transformative Education

\section{Introduction}

The COVID-19 pandemic has forced universities globally to transition into fully online delivery of course material. Undoubtedly, this has created exceptional challenges in both education generally and chemical education specifically. Recent literature documents the various approaches that instructors have adopted to deliver organic chemistry courses, as well as their different assessment methods utilized throughout the concurrent COVID-19 pandemic. One such method of instruction involved the delivery of asynchronous lectures, which included the use of video lectures and social media $[1,2]$. However, various modes of assessments were used during the COVID-19 pandemic (despite the common use of asynchronous lectures). For instance, Fung and Lam changed the assessment method of their Organic Chemistry I course to use take-home online assignments instead of regular in-class examinations [2]. On the other hand, Healy and Blade reported on the use of an artificial intelligence platform to develop online organic synthesis projects. Therein, students use retro-synthetic analysis to outline the synthesis of complex pharmaceuticals [3]. Moreover, Goodman used group oral exams to create a supportive student community and help students develop comprehensive understanding of the material [4]. When looking at a practical organic laboratory course, Fontana used the gamification of ChemDraw to investigate how an educational-game tournament (Molecule Madness) could impact the students' wellness and organic chemistry skills during the COVID-19 pandemic [5]. Others report on the challenges of online testing [6-9].

In this commentary, the author describes his mode of delivering undergraduate organic coursework at the American University of Beirut (AUB) during the spring and summer 2020 semesters. In particular, the author highlights the inclusion of special assignments in the Organic Chemistry I 
course to assess the students' learning beyond traditional examinations.

\section{COVID-19 Pandemic and Teaching Organic Chemistry at AUB}

The COVID-19 pandemic hit Lebanon in the midst of unprecedented popular revolution, economic collapse (due to the devaluation of the national currency) and general political unrest. The massive explosion of ammonium nitrate in Beirut's port on Aug 4, 2020 led to the devastation of more than a third of Beirut [10]. Teaching under such extraordinary conditions is quite challenging. Lessening the burden on students, taking into account their mental health and delivering the material online make our education mission even more taxing.

The first official COVID-19 case in Lebanon was reported on Feb 21, 2020. Consequently, the Lebanese government decided to close all schools and universities on Feb 28, 2020 (i.e. during the very early stages of the COVID-19 pandemic). This early, aggressive containment strategy resulted in the great success of Lebanon's response to the first wave of the COVID-19 pandemic [11].

The AUB was founded in 1866 in Beirut, Lebanon. AUB is a teaching-centered research university based on the American liberal arts model of higher education. AUB has over 9,000 students and 800 faculty members. The 2020 spring semester at the AUB started on Jan 22, 2020, with classes originally scheduled to end on May 2, 2020. Because of the COVID-19 pandemic, the AUB suspended on-campus activities as of March 12, 2020, with all classes being moved to a virtual environment. During said semester the author was teaching the Organic Chemistry I course to a class of 116 (mostly pre-medical) students, registered across two sections. The author had previously videotaped Organic Chemistry I lectures pertaining to a previous semester. As such, some of these videos were already posted on the author's YouTube channel [12]. Because of this, the author's transition to online teaching went relatively smoothly. In lieu of the extraneous circumstances preventing conventional methods of examination, the author informed the students on March 12, 2020 that special online assignments were going to be introduced as to properly assess their understanding of the material. Furthermore, such assignments shifted the course from a traditional mode of material delivery to a transformative mode of education [13] that stimulates students creativity, nurturers their sense of learning community, and increases their social responsibility. The first assignment was to make a short video (up to 2 minutes) illustrating any concept that was covered during the first four chapters of the Organic Chemistry I course. The first video submission was shared with all students upon that student's approval [14]. Other selected submissions included special songs explaining IUPAC naming and absolute configurations, respectively, and were posted on YouTube as well $[15,16]$. In the second online assignment, students were asked to prepare a video explaining a multiple choice question (MCQ) they created addressing the competition between the $\mathrm{S}_{\mathrm{N}} 1, \mathrm{~S}_{\mathrm{N}} 2, \mathrm{E} 1$ and E2 mechanisms. Students received prompt feedback on their questions and any misconceptions were clarified.

\section{Humor and Organic Chemistry}

Roesky and Kennepohl reported on the power of cartoons to draw the attention of students and engage them in the classroom. Such cartoons can even be more powerful than an actual lecture or regular assignment [17]. Humor is known to increase students' motivation, to enhance their rate of learning and to improve their problem solving skills $[17,18]$. Cartoons illustrating chemistry concepts were recently published on the C\&EN website [19]. In the third online assignment, students were asked to prepare cartoons to illustrate any organic chemistry concept that was already covered in the course. This assignment required deep understanding of the material, along with creativity in order to communicate the punchline of the cartoon. Selected cartoons are shown in Figure 1 and a special video showing more cartoons is posted on YouTube [20]. As for the fourth assignment, students were asked to prepare cartoons to illustrate their experience studying organic chemistry during the COVID-19 pandemic. Selected cartoons are shown in Figure 2 and a special video showing more cartoons is posted on YouTube [21]. Such activities were particularly needed during COVID-19 generally and Lebanon specifically. For these four assignments the scientific content, accuracy of explaining the concept, creativity and originality were taken into account as assessment criteria.

\section{Group Work Assignment}

Group work creates the opportunity for students to brainstorm together, synthesizing a shared understanding of the concepts and causing group engagement / learning [4]. In times of lockdown and uncertainty, students were mostly studying alone, giving them ample time to ruminate on intrusive thoughts concerning their social lives, academic futures and livelihood of their families. A recent study reported a decrease in the mental wellbeing of students, due to the increased stress, anxiety, isolation and depressive symptoms caused by the COVID-19 pandemic [22]. With this in mind, the fifth and final online group assignment was designed to give the students the opportunity to assume social responsibility and to engage in their community and outreach. The 116 students were divided into four groups of 29, each with an assigned coordinator responsible for their progress. The four groups were asked to prepare special videos related to the COVID-19 pandemic, by addressing groups of people who were particular affected by it, including: healthcare professionals, families of COVID-19 patients and those in financial struggle. The groups' coordinators were in contact with the author on a regular basis throughout the entirety of the process. These four videos were posted on YouTube upon the consent of all students [23].

During the summer 2020 semester, the author taught two 
fully online organic courses designed for nutrition and chemical engineering students, respectively. The organic chemical engineering course included a lab component as well, with the students commuting to campus to perform a total of six experiments. All safety and social distancing measures were strictly applied during said laboratories. In addition, all lectures were videotaped in a classroom environment in order to maintain the feel of an active lecture hall. The videos were then shared with the students, Figure 3. Subsequent interactive WebEx sessions were regularly conducted to solve questions related to the material using a flipped [24] classroom approach.
The WebEx pooling tool was regularly used to solicit students' answers to MCQs, which was followed by a detailed explanation of these questions by the author. Students found such online delivery of the material to be optimal and satisfying.

\section{Conclusion}

In conclusive thoughts, the forced move to an online platform mitigated what were originally sub-optimal circumstances into a transformative and creative learning environment.

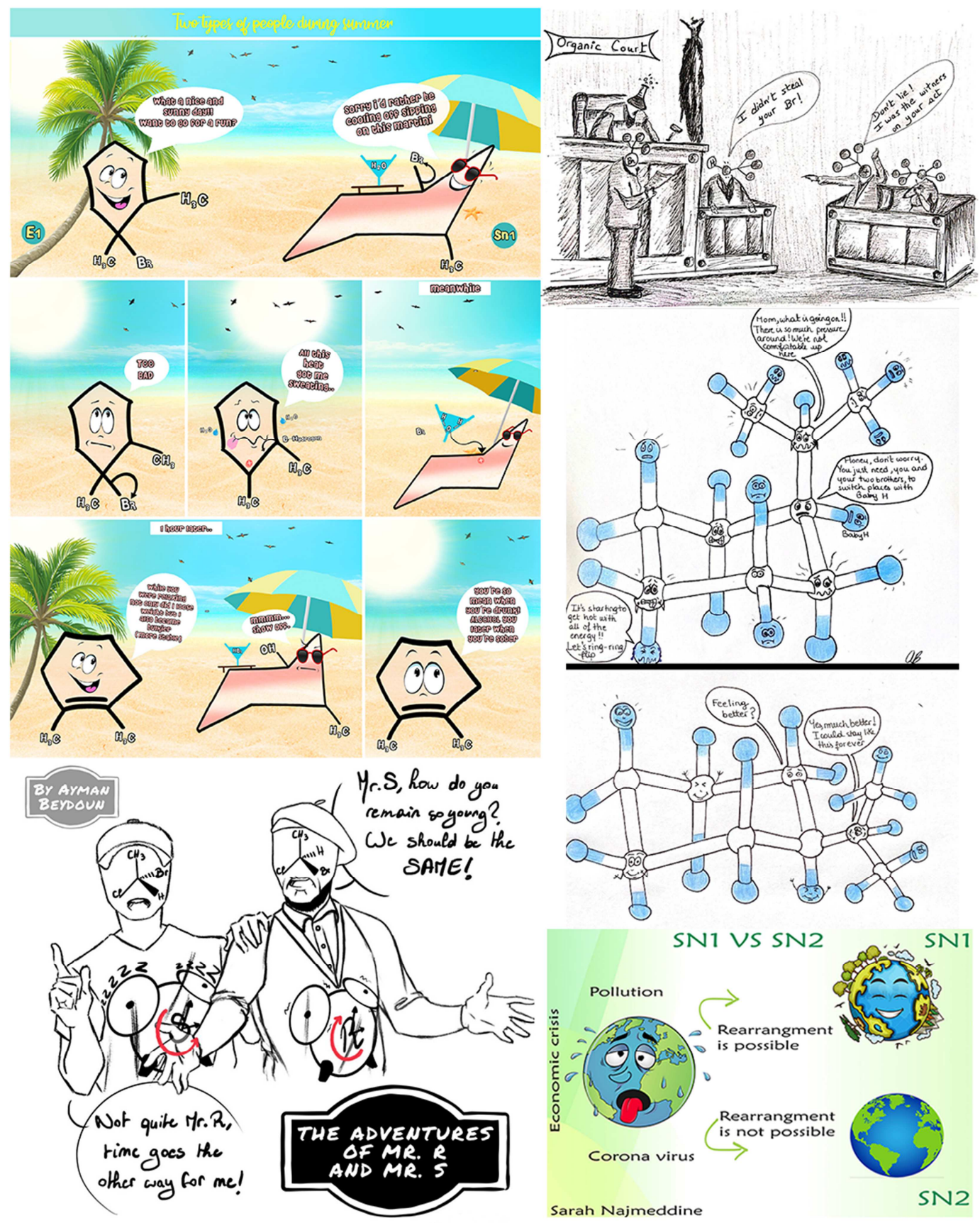

Figure 1. Selected caricatures illustrating organic chemistry concepts submitted by students taking the Organic Chemistry I course at AUB during the spring 2020 semester. Created by Joanne Zogheib (top left), Ayman Beydoun (bottom left), Reine Zankar (top right), Anna Badaro (middle right) and Sarah Najmeddine (bottom right). 

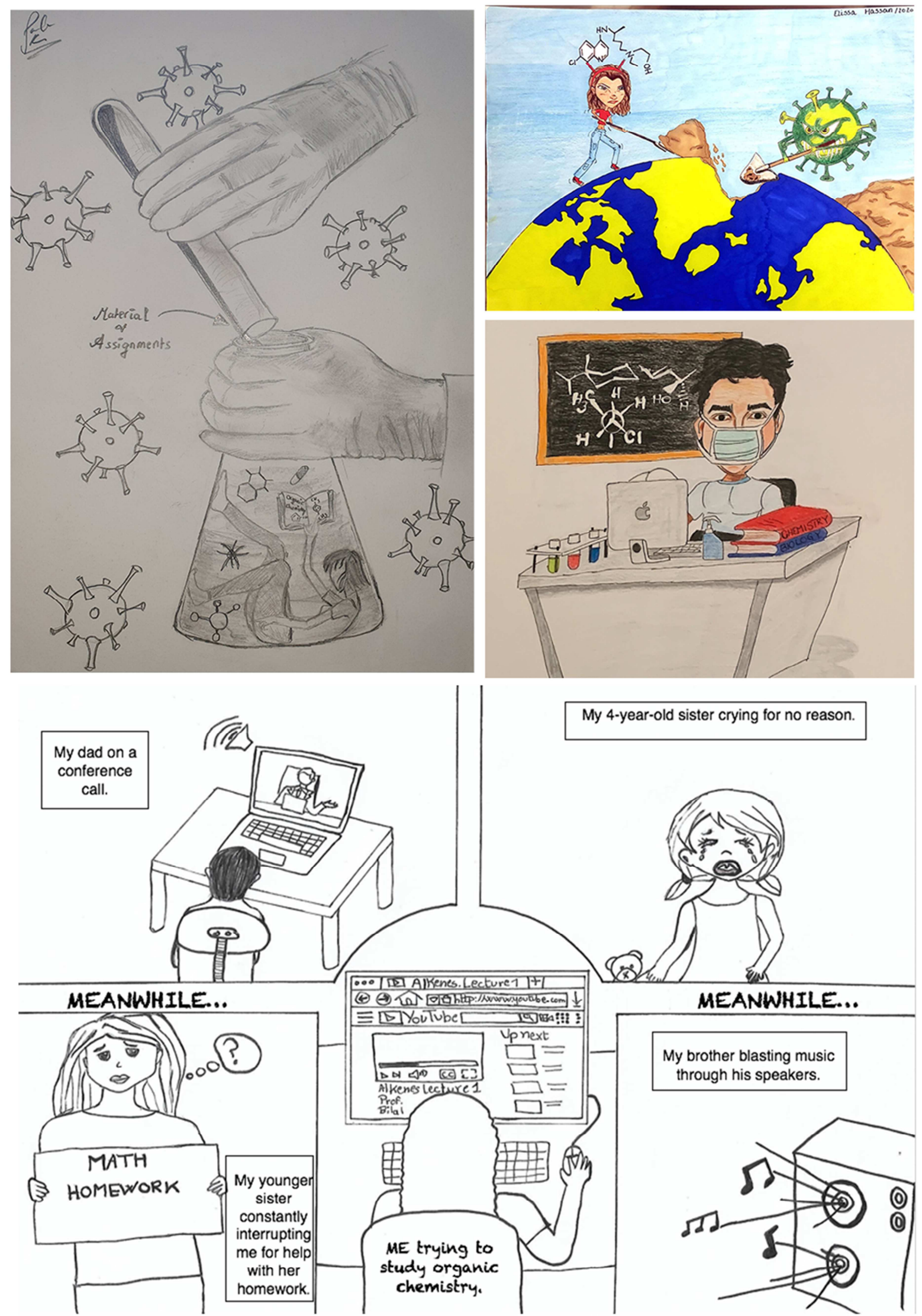

Figure 2. Selected caricatures illustrating studying organic chemistry during COVID-19 pandemic submitted by students taking the Organic Chemistry I course at AUB during the spring 2020 semester. Created by Pamela Khaswan (top left), Elissa Hassan (top right), Abduljalil Hajaig (middle right), and Layane Mekawi (bottom center). 


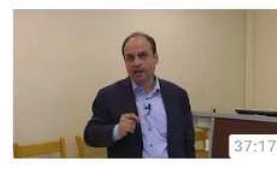

Polymers

36 views $\cdot 1$ month ago

$\oplus$ Unlisted

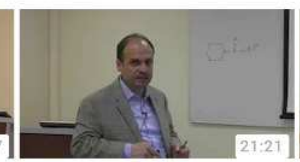

Chapter 14: Amines

70 views $\cdot 1$ month ago $\Theta$ Unlisted

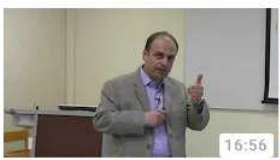

Chapter 13: Carboxylic Acid Derivatives

44 views $\cdot 1$ month ago $\Leftrightarrow$ Unlisted

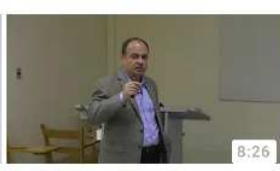

Synthesis of Isoamyl Acetate Lab Lecture

31 views $\cdot 1$ month ago $\Leftrightarrow$ Unlisted

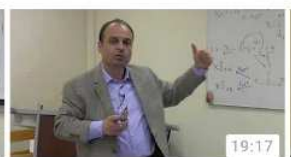

Chapter 12: Carboxylic Acids 64 views .1 month ago $\oplus$ Unlisted

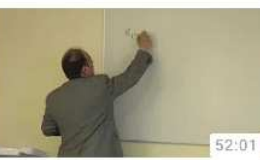

Chapter 11: Aldehydes \& Ketones

69 views $\cdot 1$ month ago $\oplus$ Unlisted

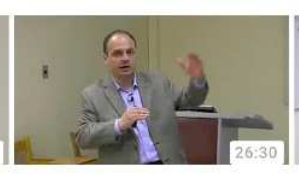

Chromatography Lab Lecture 33 views .1 month ago $\Leftrightarrow$ Unlisted

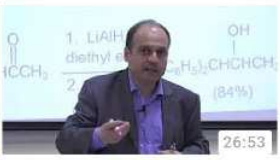

Chapter 10: Alcohols, Ethers, \& Phenols

67 views $\cdot 1$ month ago $\Leftrightarrow$ Unlisted

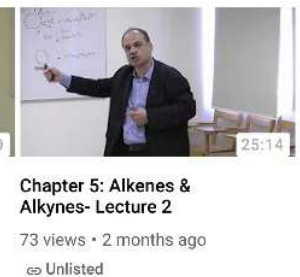

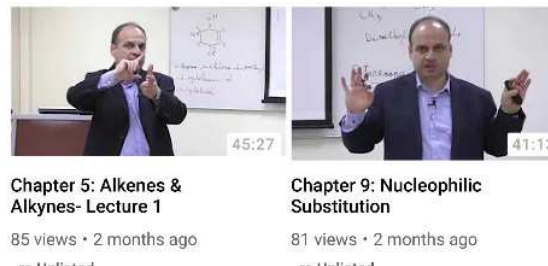

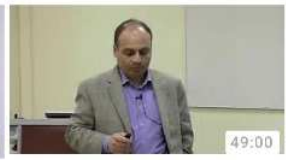

Chapter 8: Alkyl Halides Structure \& Preparation fro 130 views $\cdot 2$ months ago

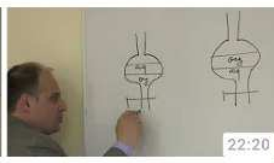

Extraction Lab Lecture 35 views 1 month ago $\oplus$ Unlisted
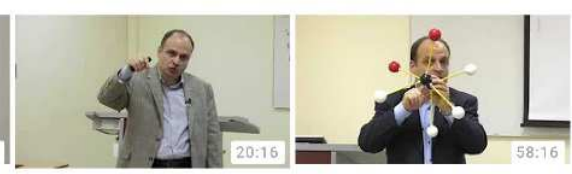

Distillation Lab Lecture 27 views $\cdot 2$ months ago $\oplus$ Unlisted

\section{Recrystallization Lab Lecture} 41 views $\cdot 2$ months ago

Chapter 4: Alkanes \& Cycloalkanes- Lecture 1 127 views $\cdot 2$ months ago $\Leftrightarrow$ Unlisted
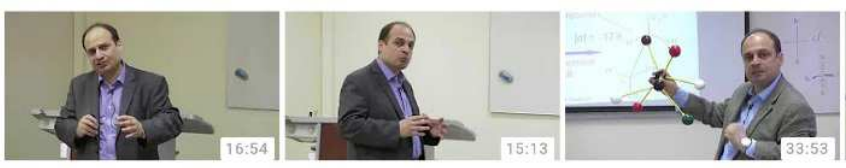
$\Leftrightarrow$ Unlisted

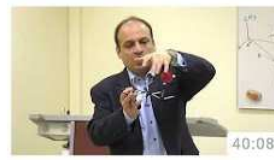

Chapter 4: Alkanes \& Cycloalkanes- Lecture 2

115 views $\cdot 2$ months ago $\hookleftarrow$ Unlisted

Organic Chemistry Recitation 70 views $\cdot 2$ months ago $\oplus$ Unlisted
Melting Points Lab Lecture 35 views $\cdot 2$ months ago $\Leftrightarrow$ Unlisted
Chem 207 Lab Safety Lecture 33 views $\cdot 2$ months ago $\oplus$ Unlisted
Chapter 3: StereochemistryLecture 2

83 views $\cdot 2$ months ago $\oplus$ Unlisted

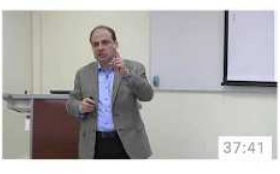

Chapter 3: StereochemistryLecture 1

110 views $\cdot 2$ months ago $\leftrightarrow$ Unlisted

Figure 3. Some of the recorded videos during the summer 2020 semester.

\section{Acknowledgements}

The author thanks all the students who took the organic courses with him during the spring and summer 2020 semesters. The author thanks Prof. Brigitte Wex and Mr. Nabil Halabi for their valuable feedback and for proof reading the manuscript. The author thanks Ayman Baydoun and Reina Akkoush from his transformative education team for designing the TOC.

\section{References}

[1] Danjou, P.-E. Journal of Chemical Education 2020, 3168.

[2] Fung, F. M.; Lam, Y. Journal of Chemical Education 2020, 2573.

[3] Healy, E. F.; Blade, G. Journal of Chemical Education 2020, 3163 .

[4] Goodman, A. L. Journal of Chemical Education 2020, 3441.

[5] Fontana, M. T. Journal of Chemical Education 2020, 3358.

[6] Clark, T. M.; Callam, C. S.; Paul, N. M.; Stoltzfus, M. W.; Turner, D. Journal of Chemical Education 2020, 3413.

[7] Crucho, C. I. C.; Avo, J.; Diniz, A. M.; Gomes, M. J. S. Journal of Chemical Education 2020, 3211.

[8] Milligan, J. A. Journal of Chemical Education 2020, 3206.

[9] Burnett, J. W.; Burke, K. A.; Stephens, N. M.; Bose, I.; Bonaccorsi, C.; Wade, A. M.; Awino, J. K. Journal of Chemical Education 2020, 2793.

[10] Guglielmi, G. Nature 2020.

[11] Khoury, P.; Azar, E.; Hitti, E. JAMA 2020, 324, 548.

[12] Author's YouTube Channel: YouTube.com/bilalrkaafarani (accessed September 2020).

[13] Achi, D. E.; Halabi, N. M.; Kaafarani, B. R. Science Journal of Education 2019, 7, 107.

[14] Video of the chirality concept covered by Zeina Al-Khalil. https://youtu.be/hx1-CU6fm_s (accessed September 2020).

[15] Video of a song by Amir Jaber Chehayeb covering IUPAC naming of alkanes. https://youtu.be/NErZ5JyAhdA (accessed September 2020).

[16] Video of a song by Joanne Rita El- Haddad covering absolute configuration. https://youtu.be/5G0Z8rT5LE8 (accessed September 2020).

[17] Roesky, H. W.; Kennepohl, D. Journal of Chemical Education 2008, 85, 1355 .

[18] Anon Science 2001, 292, 2223. 
[19] A comic collaboration between C\&EN and ChemScrapes cartoonist Brendan Burket,

thttps://cen.acs.org/sections/sketch-chemistry.html (accessed September 2020).

[20] Video of selected cartoons illustrating organic chemistry I concepts covered in the Organic Chemistry I course at AUB through the COVID-19 pandemic during the spring 2020 semester. https://youtu.be/tmcQ-XLUVY4 (accessed September 2020).

[21] Video of selected cartoons illustrating studying organic chemistry at AUB through the COVID-19 pandemic during the spring 2020 semester. https://youtu.be/NZhyW4CpjIM (accessed September 2020).

[22] Elmer, T.; Mepham, K.; Stadtfeld, C. PLOS ONE 2020, 15, $\mathrm{e} 0236337$.

[23] Group 1 video: https://youtu.be/pFA7HD2Gfc4. Group 2 video: https://youtu.be/R5FGa_Qlo1w. Group 3 video: https://youtu.be/fzDnKQgW1NY. Group 4 video: https://youtu.be/fSDpxa2vaLU (accessed September 2020).

[24] Pienta, N. J. Journal of Chemical Education 2019, 96, 1053. 